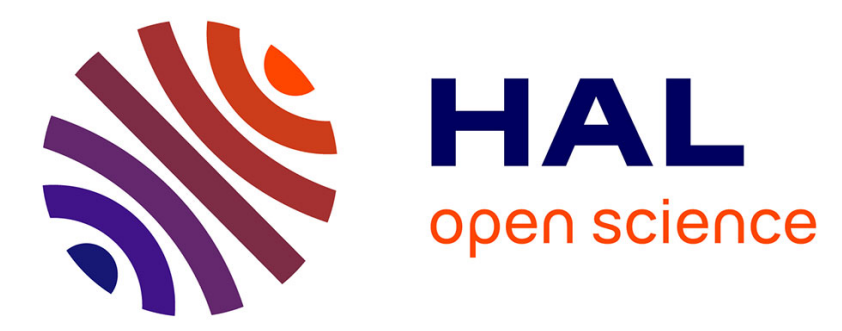

\title{
Collaborative Knowledge for Analysis Material Flow of a Complex Long Stud Using Multiple Stoke Cold Heading
}

Suthep Butdee, Uten Khanawapee

\section{To cite this version:}

Suthep Butdee, Uten Khanawapee. Collaborative Knowledge for Analysis Material Flow of a Complex Long Stud Using Multiple Stoke Cold Heading. IFIP International Conference on Advances in Production Management Systems (APMS), Sep 2015, Tokyo, Japan. pp.102-109, 10.1007/978-3-31922756-6_13 . hal-01417408

\author{
HAL Id: hal-01417408 \\ https://hal.science/hal-01417408
}

Submitted on 15 Dec 2016

HAL is a multi-disciplinary open access archive for the deposit and dissemination of scientific research documents, whether they are published or not. The documents may come from teaching and research institutions in France or abroad, or from public or private research centers.
L'archive ouverte pluridisciplinaire HAL, est destinée au dépôt et à la diffusion de documents scientifiques de niveau recherche, publiés ou non, émanant des établissements d'enseignement et de recherche français ou étrangers, des laboratoires publics ou privés. 


\title{
Collaborative Knowledge for Analysis Material Flow of a Complex Long Stud using Multiple Stoke Cold Heading
}

\author{
Suthep Butdee1,* Uten Khanawapee2 \\ 1 Depertment of Production Engineering, Faculty of Engineering \\ King Mongkut's University of Technology North Bangkok, Thailand \\ stb@kmutnb.ac.th \\ 2Department of Mechanical Engineering Technology, College of Industrial Technology \\ King Mongkut's University of Technology North Bangkok, Thailand \\ ukp@kmutnb.ac.th
}

\begin{abstract}
Productivity Improvement is one of the most important strategies for every enterprise. Head cold forging is a widely common production process which can achieve economical processes and less energy consumption. Die is the major key of the forging process but how to perform an effective design, needs several years of experiences or using engineering tools for assistance. This paper proposes the collaborative die design and analysis by combining engineering methods and industrial experts to correct problems and to validate a new and complex design. DEFORM is used to investigate suitable parameters by guidance from the expert. One of the classical problem in the head cold forging is to make a small long complex stud. It is found from simulation that a five step of punch with suitable taper angle is the most effectiveness.
\end{abstract}

Keywords: Collaborative Knowledge, DEFORM, Complex Long Stud Head Forging, Analysis Material Flow

\section{Introduction}

Cold forging aims for producing net and near-net-shape parts, such as shafts, axles, bolts, gears and so on, using room temperature. Products in different shapes and sizes are formed by high speed and high pressure processes with tool steel or carbide dies which are able to increase the hardness, yield, and tensile strengths. Cold heading is used for making screw production. It transforms wire into the designed shapes by die and punch cavities. Die is one of critical components of such processes. The force of the blow creates enough pressure to cause the metal to flow outward into a die cavity. The head or upset portion of the part is larger in diameter than the original billet. It commonly deforms aluminum, carbon and alloy steels. Presently, cold forging can produce $\pm 0.025 \mathrm{~mm}$. of tolerance. The process is applied for producing nuts, bolts, screws, rivets, and other fasteners. Complex shapes of products require multi-step of cold heading or combine with other processes. Consequently, the blows may be struck, with the billet moving through a sequence of dies. Extrusion is one of the effective process applied to assist the cold forging for creating the ratio of head to shank size beyond the normal cold heading capability. Cold heading shape design can be single blow headers or double blow headers. The single blow headers are the simplest and fastest process.

adfa, p. 1, 2011.

(c) Springer-Verlag Berlin Heidelberg 2011 
They can produce hundreds of pieces per minute but are limited to minor shank extrusion and simple head shapes using a single stroke machines which a wire roll is sheared in a die, struck one blow, and ejected. The process type is suitable for the material lends itself easily to upsetting. Hard materials are deformed by double blows. The first punch delivers the metal flow. The shape is completed with the second blow. Double stoke headers are necessary when the diameter of the head is more than two sizes. The large heads of a nut needs multi-die machines and multiple step cold heading process. Multistation or progressive headers are used, when many strokes are required for more complicated contours dies [1].

In our work recently, university-industrial collaboration is preferable to Thai-government policy. In production engineering department and department of tool and die are concentrated on material flow analysis using DEFORM, a commercial software. Different types of products, processes and material flow of cold and hot forging are captured for knowledge. It is rarely used and validated even on the real-time problem solving. In this case of research study, collaborative works of specialist CAE lab engineer and industrial die design expert team are on-line discussing via a suitable social media platform that will be explained in a next section. Industry has received more and more complex and hard shapes of products. The paper proposes and discusses an analysis of material flow for a long stud via a line environment. Such product needs a multi-stoke machine together with progressive die and punch. DEFORM, is applied to solve problem of material flow in a particular shape, size, and its tolerances. The knowledge of die and punch design has been built in the library before being used and routinely updated by both sides. A collaborative design process is created via a common social network on their own smart mobile phones. Therefore, A LINE network is created in group in order to share knowledge and ideas. Including some parts of solving solutions before they have been stored in the database library.

\section{Related Works and Problems}

This section presents previous works which relate to our paper and defines scope of study. Im et al. [2] presented computer aided process design in cold-former forging of ball joint using a forging simulator and a commercial CAD software. The forging sequence design and its detail design are generated interactively from a design database, knowledge-based rules and basic laws. The simulation technique is used for verification. Die set design and die manufacturing information are generated automatically. Such techniques can improve productivity. Kim and Im [3] proposed an expert system for multi-stage cold-forging process design with a re-designing algorithm. The system consists of a user interface, a system shell, a material data-base, and a design rule-base. The system developed is able to reduce trial-and-error by design engineers in determining forging parameters. Stephen and Vollertsen [4] presented a laser-based micro upsetting process which takes advantage of scaling effects to optimize the conventional multi-stage upsetting. In conventional process, it is risk of bulking and cracks, whereas the laser-based process separate treatment process between the upsetting steps omitted. MaCormack and Monaghan [5] proposed the FEA of clod forging die using two and three dimensional models using DEFORM. The result showed contact and friction. 
Finding that the highest stress concentration occurred within the body of the tool and not along the contact surface. Weroński et. al. [6] explained research of upsetting ratio in forming processes on a three slides forging press. Hussain et. al [7] proposed a study on cold forging die design using different techniques. Danno et.al. [8] proposed multistage cold forging of thin-walled components. The case studies were conducted through FE simulation and experiments. The result showed that the process was effective to reduce the forming load and improve flow in the forming of two kinds of thin aluminum alloy components with multi thickness. Tae-Wan Ku et. al.[9] proposed multi-stage cold forging and experimental investigation for the outer race of constant velocity joints. Joun et.al [10] presented an application-oriented finite element approach to forging die structural analysis. Stress on tools and work pieces are the critical problems in cold forging processes which may cause fatigue cracks. Several experimental and numerical have been studied on the fracture and estimations of service life of forging tools. However, little research is on the complex stud analysis using tool steel and hard steel. It rarely presented collaborative sharing knowledge between university and industry in aspect of real time and on-line. The next section explains the collaborative model.

Industrial knowledge is indispensable context for improving productive and competitive enterprises. Particularly in the area of tools and die design because it needs many years of learning by their own experiences. In addition, different areas requires alter knowledge and know-how. In the aluminum extrusion die design requires a specific knowledge together with global collaborative working group [11, 12, 13, 14]. Knowledge is able to manage in different types. Case-based reasoning is well known and suitable for industrial knowledge because it can learn knowledge more from the previous experience comparing theory general basic knowledge and adapt to fit to solve new problems quickly $[15,16,17]$. Knowledge management plays an important role of an advanced enterprise. Basically, knowledge can be explicit and implicit but need to capture and store in a well-structure system. Capitalization knowledge is a critical part of knowledge management [18, 19, 20, and 21].

\section{Collaborative University and Industry system}

In some areas of cold forging design needs a lot of experience in order to improve productivity, quality and efficiency. Presently, customers can easily link to global sourcing and need a manufacturer to response satisfactory and competitively in aspects of cost and time. This paper proposes a creative model which collaborate among involving workforces. They are design knowledge engineer, advisor and industrial knowledge designer via a common social media, LINE tool. Problems comes to industrial design department all the time of working day, and it is time consuming to solve such problems. It routinely uses narrow scope of experience. The company's need is to improve productivity and increase more competitiveness by sharing problems and solutions. Fig. 1 shows the collaborative design system which composes of three main players; the industry design engineer, the university advisor and the lab knowledge engineer. They are all participants via LINE environment. The problem-solving procedures and solutions are stored in the knowledge base which can be useful as a reference 
and future use on both sides. The lab knowledge engineer can perform a new experiment shortly, whereas the industry design engineer can trial a new process whenever the production line is available.

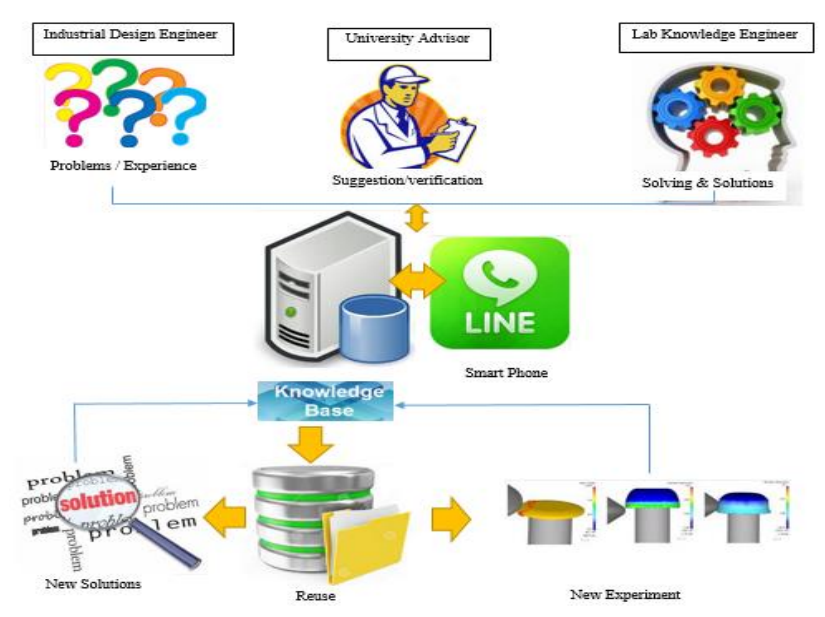

Fig.1. Collaborative knowledge design system

Figure 1 shows the collaborative knowledge design system. It is the simplest communication media system using LINE which popular in Thailand. New specific problems (products) coming from customer which are different from the previous parts are posted in the LINE group linked to every member on their smart phones. The LINE is interfaced to the knowledge base library which attracts the useful knowledge in a certain format. The solution is divided into two categories; real-time and storage. Some experience problems can be provided directly by specialists whereas the other some need time to analysis. Storage knowledge is retrieved from library. Some new solution which is invested from diary performance will be recorded in the new solution part of the memory. On the other hand, the new experiment which existed from the lab will store the new experiment part. Both parts of memory are linked to the knowledge base library (KBL). However, the KBL requires an effective management to share and not share information. It is defined as public and private sections.

\section{Experimental Study}

The case study selected to show how problems can be solved by collaborative model. A long small complex stud using 1035 (S35C) as shown in the Fig.1. The present facing problem is that the material has blended because of the length of work-piece. The collaborative team is discussed and agreed that the process should be increased one more step of deforming. Process change causes risk of failure and take more time to solve problems. Fortunately, the collaborative method can reduce the risk and time saving. The session presents the new process of the developed model. The team members agree 
to start with the three punch and three die process. It consists of a body and steps on the head and tail. The difficulty areas are the chafer and fillet. They are very small and have close tolerances.
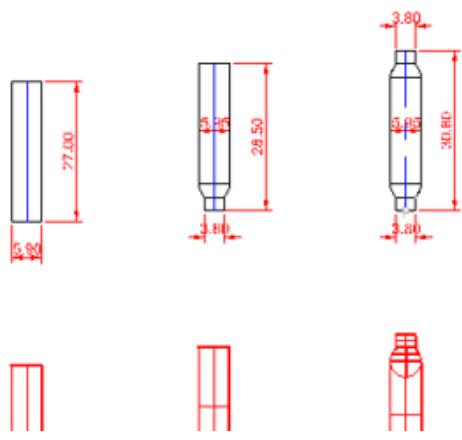

岁
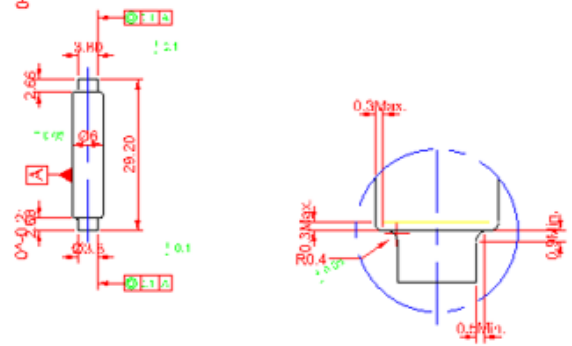

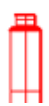

Fig. 2. Example of a long small complex stud heading part

DEFORM of CAE is taken into account for the three punch and three die process analysis. The parameter assigned for heading speed is $300 \mathrm{~m} / \mathrm{s}$ and fiction coefficient is 0.08 . The first experiment on the $150^{\text {th }}$ step. The heading process is stopped. It is because a shock size reduction. The design expert suggests that heading step should be increased. The knowledge engineer takes the five punch and five die process with the concave size reduction.

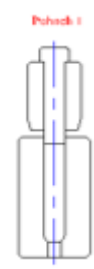

Dio 1

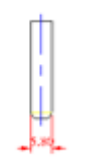

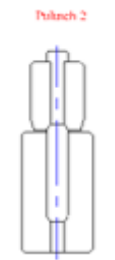

$1 \infty 2$

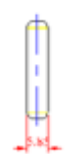

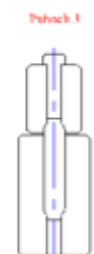
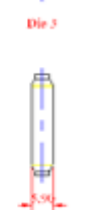

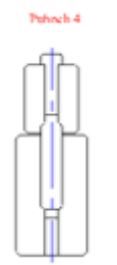

Diet

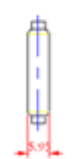

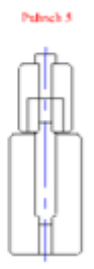

niens

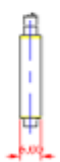

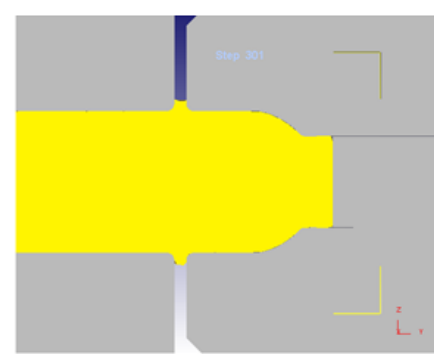

Fig. 3. The second experiment of using the five punch and five die process

The Fig. 3 illustrates the result of the second experiment. The flashing problem still occurs in the third die of the $301^{\text {st }}$ step. The expert further suggests that the second die 
should be modified to increase more area on the straight line of material flow as well as to increase taper area.

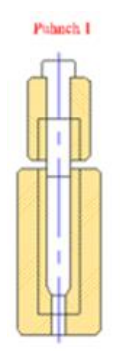

Dei

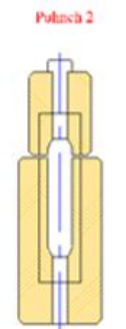

Die 2

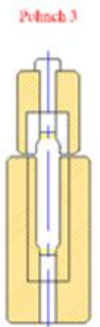

Die 3

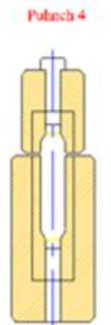

Dies

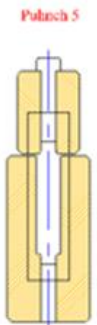

Dies

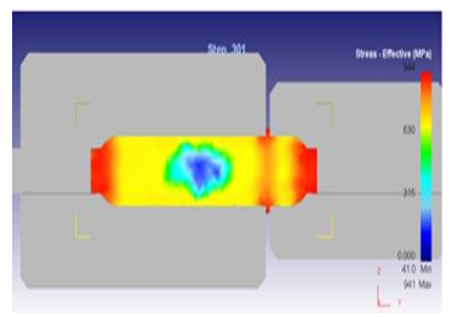

Fig. 4. The five punch and five die with the first modification

Fig. 4 shows the third experiment of using five punch and 5 die process with the first modification. It is found that the billet could not go through. It occurs a flashing problem in the third die. The collaborative team is then agrees to modify as an opening die. The billet is formed to become tapers on both sides. The second die is modified by increasing on the straight flow line to support the billet.

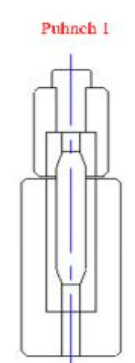

bie 1

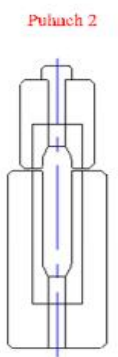

Die 2

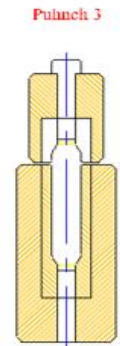

Die 3

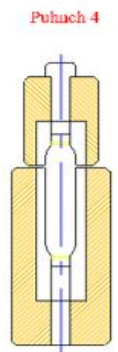

1)ie 4
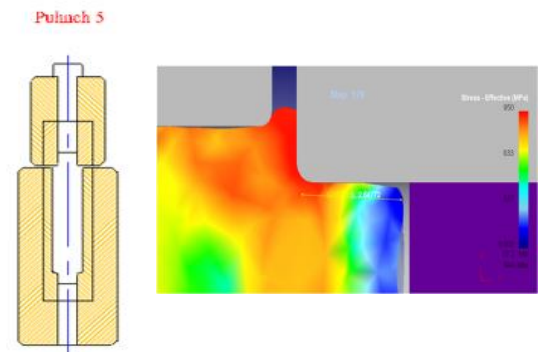

13ie 5

Fig. 5. The five punch and die process with the second modification

Fig. 5 shows the result of the forth experiment. It is still having flashing problem on the fifth die. The expert suggests that the punch 2 and punch 4 should be modified. The angle must be reduced smaller than the former in order to improve a better flow inside the third die. In addition, the straight line area must be extended to protect distortion. 


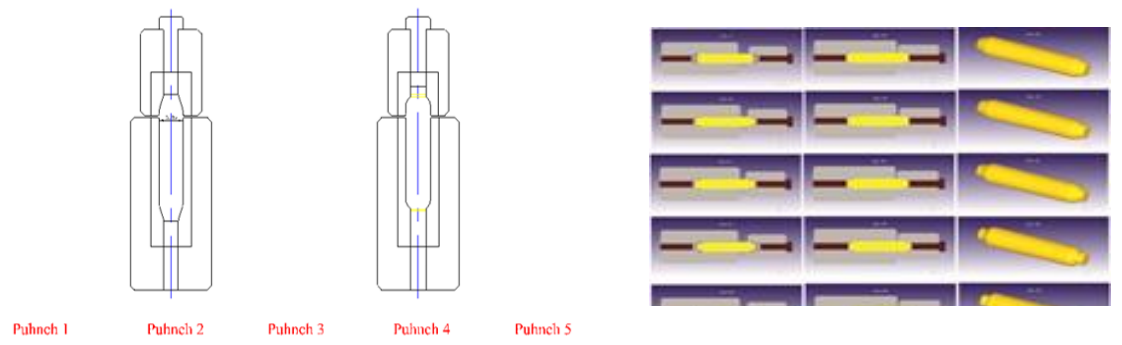

Fig. 6. The final modification and its result

Fig. 6 shows the final modification which the second and third die are modified. The second die should be a very small angle of orifice whereas the fourth die must have very long straight line area in order to support the billet while is flowing through the whole die.

\section{Concluding Remarks}

The new concept of collaborative knowledge for analyzing material flow of a long complex stud using multi stoke cold heading has been presented. The cold heading die process design is discussed followed by the related works and problems statement. The collaborative industrial design is also expressed. The proposed development system is shown. A selected case experiment study is presented. A small long complex stud is experimented and investigated the best result from the collaborative team. It is only the fifth time of trial on the DEFORM software and can achieve a well-result to guide the industrial design engineer. This method impacts productivity and is less time consuming to reach an effective design and manufacturing.

\section{References}

1 http://www.nickelinstitute.org/

2 Im. C.S., Suh. S.R., Lee. M.C., Kim. J.H. and Joun. M.S. (1999) Computer aided process design in cold-former forging using a forging simulator and a commercial CAD software. Journal of Materials Processing Technology 95 (1999) 155-163.

3 Kim.H.S. and Im.Y.T. (1999) An expert system for cold forging process design based on a depth-first search. Journal of Materials Processing Technology 95 (1999) 262-274.

4 Stephen.A., and Vollertsen.F. (2010) Upset Ratio in Laser-based Free Form Heading. Physics Procedia 5, 227-232.

5 Conor M.C.and Monaghan J. (2001) A finite element analysis of cold forging dies using two and three dimension models, Journal of Material Processing Technology $118(2001286-292$. 
6 Weronski, W.s., Gontarz and Pater, Z. (2006) Research of upsetting ratio in forming processes on a three - slides forging press. JAMME, VOLUME 17. ISSUE 1-2. JulyAugust 2006.

7 Hussain.K., Samad.Z., Othman.A.R., Salman.A.N.J., Basruddin,I.A. and Hakim.S.S. (2009) A Study on Cold Forging Die Design Using Different Techniques. Modern Applied Science, Vol. 3, No. 3. 143-154.

8 Atsuahi Danno*, Sebastian Berner, Kai Soon Fong, Wai Tang Yap (2014), Multistage cold forging of thin-walled components, Procedia Engineering 81, 407 - 412.

9 Ku.T.W., Kim.L.H., and Kang.B.S (2013) Multi-stage cold forging and experimental investigation for the outer race of constant velocity joints, Materials and Design 49 (2013) 368-385.

10 Joun.M.S., Lee.M.C., Park J.M. (2002) Finite element analysis of presented die set in cold forging, International Journal of Machine Tools \& Manufacture 42 (2002) 1213-1222.

11 Tichkiewitch. S., Butdee.S.and Phillip Marin (2002) Knowledge Management for the design of dies in aluminum extrusion process, The Proceeding of 2002 International CIRP Design Seminar.

12 Butdee. S., Noomtong. C., Vignat, F. and Thomann. G. (2007) Methodology of Knowledge Library Management for Concurrent Cooperative Design, Proceeding of the $24^{\text {th }}$ International Manufacturing Management. Vol.2, 711-718.

13 Pimapunsri. K., Butdee. S and Tichkiewitch. S. (2008) Industrial Knowledge Management using Collaborative Knowledge Acquisition in a Consultancy Project, Journal of Achievements in Materials and Manufacturing Engineering, pp.803-809.

14 Pimapunsri. K., Tichkiewitch. S. and Butdee. S. (2008) Collaborative Negotiation between Designers and Manufacturers in the Wood Furniture Industry using Particleboard or Fiberboard, The $15^{\text {th }}$ CIRP International Conference Design,

15 Janthong. N., Brissaud, D. and Butdee, S. (2009) Knowledge-based Adaptable Design to Support Customer-Oriented Production System of Industrial Equipment. The $42^{\text {rd }}$ CIRP Conference on Manufacturing Systems.

16 Janthong. N., Brissaud, D. and Butdee. S. (2009) Combining Axiomatic Design and Case-Based Reasoning in a Design Methodology of Mechatronics. The Proceeding of 2009 CIRP Design Conference.

17 Butdee. S., Noomtong. C., Tichkiewitch. S. (2010) "Collaborative Aluminum Profile Design to Adaptable Die Process Planning Using Neural Networks ", Key Engineering Materials, vol. 443, pp. 207-212.

18 Hirunyasiri. V. and Butdee. S. (20130 Knowledge Synthesis Using Multichannel of Media in the Case Study of Integrated Circuit Industry, KMUTNB: International Journal of Applied Science and Technology 6 (1), 67-79

19 Butdee. S. (2010) Case-based formulation to knowledge capitalization for plastic injection mold design, IEE IEEM. 934-939.

20 Butdee. S and Tichkiewitch. S. (20110 Global Product Development, Springer Berlin Heidelberg. 491-496

21 Numthong. C. and Butdee, S. (2013) The Knowledge Based System for Forging Process Design based on Case-Based Reasoning and Finite Element Method. KMUTNB: International Journal of Applied Science and Technology 5 (2), 45 54. 